\title{
Incidencias de la Toxicosis
}

Profesor Luis María Ferro. Jefe de Clinica: Luis Salazar Dávila. Interno: Luis Francisco Rozo.

\section{Albuminuria gravídica o preeclampsia leve}

Hecha la revisión de todas las historias clínicas de las pacientes ingresadas en el período de 1942 a 1952. sobre el total de 64.297 historias se encontraron 1.174 correspondientes a pacientes toxémicas, lo cual da un indice general de toxemia de $1.82 \%$.

De estas, 137 corresponden a albuminurias gravídicas o sea el 11.66\%, 622 fueron preeclápticas, o sea $52.98 \%$ y 415 fueron eclámpticas, o sea 35 a $36 \%$.

Enfocando cada una de estas tres entidades por separado, con el objeto de buscar incidencia entre nosotros, se nota que en albuminuria gravídica la mayor frecuencia se encuentra en las primigestantes $(53.28 \%$ ) y el resto $44.52 \%$ para las multiparas, descontando un $2.19 \%$ correspondiente a pacientes en cuya historia no se anotó el número de la gestación.

En relación con la edad de las pacientes la mayor frecuencia está comprendida entre los 20 y los 25 años $(34.30 \%)$ ) sigue luégo las de 15 a 20 años $(27.73 \%)$. Vienen en seguida las de 35 a 40 años $(13.13 \%$ ) y por último las mayores de 40 ( $5.83 \%)$; se descarta un $2.18 \%$ cuya edad no fue anotada.

Con respecto a la edad de la gestacion el mayor índice, $72.26 \%$, corresponde a mbarazos de 8 a 9 meses; el $23.14 \%$ corresponde a embarazos de 6 a 8 meses y el $45 \%$ a molas hidatidiformes. Se descartan igualmente $2.92 \%$ de historias en las cuales faltó la anotación de la edad de la gestación.

De estas albuminurias. $67.88 \%$ tuvieron edemas, y $23.35 \%$ no los tuvieron, quedando un $8.65 \%$ de cásos no especificados.

En la tasa total de la albuminuria la mayor frecuencia corresponde a cantidades menores de 2 gramos.

En relación con la vitalidad fetal se puede anotar que el $89.78 \%$ de las pacientes llegaron con fetos vivos, el $5.11 \%$ con feto muerto, $1.46 \%$ con mola hidatidiformes, y en el resto $3.65 \%$ se dejó de anotar el estado del feto a su ingreso al Instituto. La mortalidad materna fue de $0 . \%$. La mortalidad fetal alcanzó a $14.60 \%$.

\section{Pre-Eclampsia}

Entre los 622 casos encontrados las pacientes comprendidas entre los 20 y los 25 años de edad. pagan el mayor tributo con una frecuencia de $27.97 \%$. Siguen las de 15 a 20 años con $25.88 \%$ y de los 30 años en adelante sólo alcanzan al $2.89 \%$. 
Se observa pues que la frecuencia disminuye con la edad y con la multiparidad; como lo demuestra el hecho de que el $49.83 \%$ corresponde a las primigestantes y el $50.77 \%$ al total de las multiparas.

Como en la albuminuria la mayor frecuencia de la preeclampsia corresponde a gestaciones entre 8 a 9 meses de edad, alcanza a un $76.78 \%$.

La frecuencia de los distintos sintomas puede resumirse asi: cefálea $70.25 \%$; siguen después los edemas, los vómitos y la constipación; en cuanto a la albuminuria las tasas menores de un gramo son las más frecuentes, con cilindruria y hematuria ligeras casi constantes; la tensión arterial es siempre elevada encontrándose máximas por encima de 140 milimetros, como primer signo de alarma.

En cuanto a la vitalidad fetal se encontró que el $93.08 \%$ de las pacientes ingresadas llegaron con feto vivo y sólo el $5.14 \%$ tenian el feto muerto, quedando $1.76 \%$ de pacientes en las cuales no se anotó el estado de feto en el momento de su llegada.

En el $74.75 \%$ de los casos se empleó exclusivamente el tratamiento médico. La cesárea se practicó en $4.62 \%$. Las aplicaciones de forceps se hicieron en un $10.16 \%$ y lá extración podálica en el $1.60 \%$ : para mayor protección de la madre, en los casos de feto muerto, se emplé el basiotribo en $1.60 \%$.

El índice de mortalidad materna por preeclampsia sobre la totalidad de los casos de toxicosis da un $1.92 \%$ y dentro del grupo preeclampsia un $3.05 \%$; la mortalidad total alcanzó a $10.12 \%$.

\section{Eclampsia}

Se presentó en 436 casos distribuidos asi: eclampsia del embarazo 34,63\%; aclampsia del parto $47.93 \%$ y eclampsia del puerperio $17.43 \%$.

Como en los casos anteriores la mayor frecuencia corresponde a las jóvenes de 15 a 20 años, que alcanza al $36.06 \%$, para ir disminuyendo a medida que aumenta la edad de las pacientes. El 60.48\% corresponde a primegestantes y $35.90 \%$ a las multíparas quedando un residuo de $6.02 \%$ que no fue anotado. Los mayores índices corresponden a embarazos entre 8 y 9 meses, $69.05 \%$.

El síntoma más frecuente fueron las convulsiones que ocurrieron en $82.65 \%$ de los casos. Luégo los edemas $46 \%$ y por último el delirio, la obnubilación, en $31.08 \%$.

Por la observación general de los datos reunidos, se observa que las albuminurias bajas, hasta 2 gramos, son las que con mayor frecuencia conducen a la eclampsia; a esta tasa corresponde $79.99 \%$ de los casos, de los cuales en el $43.52 \%$ sólo había huellas de albúmina.

El estado del feto al entrar al Instituto fue bueno en el $76.09 \%$, regular $7.04 \%$ y llegaron muertos el $16.05 \%$. Se aplicó tratamientó médico exclusivamente en $60.48 \%$, se intervino por cesárea el $17.10{ }^{\circ}$ y con forceps el 17.10 \%" se practicó la versión interna en $0.96 \%$ y la extracción podálica en $0.48 \%$ de los casos, y en el mismo porcentaje o sea $0.48 \%$, se aplicó la embriotomía en feto muerto.

La mortalidad materna alcanzó al $21.44 \%$ dando el mayor índice en todo el grupo de toxemias; la mortalidad fetal fue $39.52 \%$. 